\title{
Chemistry of Hyphal Walls of Phytophthora
}

\author{
BY S. BARTNICKI-GARCIA \\ Department of Plant Pathology, University of California, \\ Riverside, California, U.S.A.
}

(Received 7 July 1965)

\section{SUMMARY}

Hyphal walls of two phytopathogenic moulds, Phytophthora cinnamomi and $\boldsymbol{P}$. parasitica, were isolated essentially free from cytoplasmic contamination. They have a complex chemical structure consisting of polysaccharide, protein and lipid. D-Glucose was the main monosaccharide detected in acid hydrolysates. Chromatographic evidence suggested the presence of small amounts of mannose $(0 \cdot 6 \%)$, glucosamine $(0 \cdot 3 \%)$ and traces of galactosamine and ribose. Glucans constituted nearly $90 \%$ of the wall but only about a maximum $25 \%$ of the wall could be regarded as cellulose I on the basis of solubility, resistance to hydrolysis and X-ray diffraction. Most of the wall glucan exhibited chemical and physical properties unlike typical cellulose.

The spectrum of amino acids commonly found in fungal walls was detected; hydrolysates also contained hydroxyproline and two minor unidentified ninhydrin-positive components. Protein comprised 3-5\% of the wall. A small amount of lipid (1-3\%), mostly of the bound type, was found, and also traces of phosphorus, and compounds with absorption maxima at $263 \mathrm{~m} \mu$. Hyphal walls of Phytophthora cinnamomi and $\boldsymbol{P}$. parasitica differed only slightly in quantitative composition.

\section{INTRODUCTION}

Customarily the cell walls of filamentous fungi are described as chitinous or cellulosic. The grouping of fungi based on the presence of either one or, in some cases, both of these polysaccharides, parallels taxonomic demarcations (Wettstein, 1921; Frey, 1950; Fuller \& Barshad, 1960; Aronson \& Preston, 1960). With the availability of physical methods for isolating cell walls, the chemical complexity of the walls of fungi has now been clearly realized. In addition to chitin or cellulose, various carbohydrates, proteins, lipids, and other components have been found in the cell walls of moulds (Kreger, 1954; Aronson \& Machlis, 1959; BartnickiGarcia \& Nickerson, 1962; Crook \& Johnston, 1962; Hamilton \& Knight, 1962; Bartnicki-Garcia \& Reyes, 1964; Horikoshi \& Iida, 1964; Russell, Sturgeon \& Ward, 1964; Potgieter \& Alexander, 1965; Wessels, 1965; etc.). The majority of filamentous fungi have chitinous walls. Quantitative studies of wall chemistry in several such fungi have already been reported, but hitherto no comparable studies on cellulosic fungi had been made.

Phytophthora, a notorious genus of plant pathogens, is a prominent example of the relatively few fungi with cellulosic walls. The presence of cellulose in the phytophthora mycelium, long claimed (Dastur, 1913), was definitely established through X-ray analysis by Frey (1950). More recently Crook \& Johnston (1962) 
made a qualitative survey of sugars and amino acids in the cell walls of fungi, including Phytophthora cactorum. The present communication, describing the quantitative composition of hyphal walls of two phytophthora species, is an initial study designed to gain insight into the morphogenetic role of cell-wall chemistry in the life-cycle of these plant pathogens. A strain of Phytophthora cinnamomi parasitic on avocado, and a strain of $\boldsymbol{P}$. parasitica pathogenic to citrus trees, were selected from among various other phytophthora strains and species tested; the choice was made on the basis of the relative facility with which hyphal walls could be isolated with a minimum of cytoplasmic contamination.

\section{METHODS}

Microbiological techniques. Phytophthora cinnamomi Rands strain sB 216-1 and Phytophthora parasitica Dastur strain $\mathrm{T} 89$ were isolated and kindly given by Drs G. Zentmyer and P. Tsao from this Department. Stock cultures were maintained on V-8 juice agar slants. Liquid V-8 medium was prepared with the clear supernatant fluid of centrifuged V-8 juice (Campbell Soup Co., Camden, New Jersey), diluted $1 / 4$ with glass-distilled water and its $\mathrm{pH}$ adjusted to $6 \cdot 3$ with KOH. V-8 juice agar plates were inoculated and grown for about a week at $27^{\circ}$. Disc plugs were removed from the periphery of growth with a sterile stainless-steel cork borer and inoculated into $350 \mathrm{ml}$. prescription bottles containing $40 \mathrm{ml}$. of the following asparagine glucose medium: $\mathrm{KH}_{2} \mathrm{PO}_{4}, 3 \mathrm{~g}$.; $\mathrm{CaCl}_{2}, 3.4 \mathrm{mg}$.; $\mathrm{FeSO}_{4} \cdot 7 \mathrm{H}_{2} \mathrm{O}, 1 \cdot 0 \mathrm{mg}$., with citric acid, $1.4 \mathrm{mg}$.; $\mathrm{ZnSO}_{4} .7 \mathrm{H}_{2} \mathrm{O}, 1 \cdot 8 \mathrm{mg}$.; $\mathrm{MnSO}_{4} . \mathrm{H}_{2} \mathrm{O}$, $0.3 \mathrm{mg}$.; $\mathrm{CuSO}_{4} .5 \mathrm{H}_{2} \mathrm{O}$, 0.4 mg.; $\left(\mathrm{NH}_{4}\right)_{6} \mathrm{Mo}_{7} \mathrm{O}_{24} .4 \mathrm{H}_{2} \mathrm{O}, 0.3 \mathrm{mg}$.; $\mathrm{MgSO}_{4} .7 \mathrm{H}_{2} \mathrm{O}$, 0.5 g.; thiamine $\mathrm{HCl}, 1.0 \mathrm{mg}$; L-asparagine, 2 g.; glucose, $20 \mathrm{~g}$.; glass-distilled water to $1000 \mathrm{ml}$. Glucose in concentrated solution was autoclaved separately and added to the rest of the ingredients which had been previously adjusted to $\mathrm{pH}$ 6.0 with $\mathrm{KOH}$ and autoclaved for $20 \mathrm{~min}$. at $121^{\circ}$. Inoculum bottles were incubated at $27^{\circ}$ for about 5-7 days. Mycelial mats from 5 bottles were placed in a sterile cup of a Servall Omni-mixer and homogenized at medium speed for a few minutes. The homogenized mycelium was centrifuged, washed once with culture medium solution and inoculated into 8 2-1. flasks containing $600 \mathrm{ml}$. asparagine glucose medium. These flasks were placed on a rotary shaker and agitated 5 days at $27^{\circ}$. The mycelium was filtered through a sintered glass filter, washed with distilled water and lyophilized.

Isolation of cell walls. The mycelium of Phytophthora cinnamomi prepared as above was suspended in water $(0.5-1.0 \mathrm{~g} . / 35 \mathrm{ml}$.) and blended in a Virtis ' 45 ' homogenizer at full speed and centrifuged at $1400 \mathrm{~g}$; the supernatant fluid containing cytoplasmic debris was removed. The residues were combined and suspended in $20 \mathrm{ml}$. water $/ \mathrm{g}$. initial mycelium. Samples $(10 \mathrm{ml}$.) were withdrawn and placed in the cup of a 10 kcyc. Raytheon Sonic Oscillator with $15.5 \mathrm{~g}$. glass beads (150 $\mu$ average diameter). The resulting paste was treated at full power for $5 \mathrm{~min}$. Sample temperature was maintained at $0-20^{\circ}$ by circulating coolant at $-5^{\circ}$. Two to four treatments sufficed to obtain satisfactory breakage. Glass beads were separated by decantation. Cell walls were then spun down at $1400 \mathrm{~g}$ for 5 min. and the supernatant fluid, consisting chiefly of cytoplasmic debris, was discarded. The residue containing wall fragments of different size and cytoplasmic 
debris was divided into 8 portions, suspended in $30 \mathrm{ml}$. water each, and homogenized in an Omni-mixer for 30 sec. at half speed. These wall suspensions were fractionated by a series of consecutive $1 \mathrm{~min}$. centrifugations at 50, 210, 500,900 and $2000 \mathrm{~g}$. Each residue was resuspended and centrifuged at the same speed as when first sedimented and the resulting supernatant fluid combined with the residue sedimenting at the next higher speed. The entire procedure was repeated twice. In this way, wall fractionation according to size was achieved; the heavier fractions, sedimenting at 50 and $210 \mathrm{~g}$, contained large wall fragments with some hyphal segments partially filled with cytoplasm and glass particles. The lightest pellet $(2000 \mathrm{~g})$ contained minute wall pieces mixed with fine uncharacterized particles; the fractions sedimenting at 500 and $900 \mathrm{~g}$ contained the purest walls as revealed by staining with Lugol's iodine solution. Walls were lyophilized and stored in a freezer. The hyphal walls of $\boldsymbol{P}$. parasitica were more difficult to prepare because of a tendency of wall fragments to agglutinate in big clumps after the first washings, making subsequent differential centrifugation impossible. Instead, walls were subjected to repeated treatments in the sonic oscillator (without glass beads) rapidly followed by centrifugation at $210 \mathrm{~g}$ for $1 \mathrm{~min}$. In this manner, cytoplasmic contaminants were gradually discarded with the supernatant fluids. Treatments were continued until light microscopy revealed practical disappearance of cytoplasmic debris.

Chemical analyses. Three types of hydrolysates were prepared. (a) $\mathrm{N}_{2} \mathrm{H}_{2} \mathrm{SO}_{4}$ hydrolysate. Wall suspensions (2 mg. $/ \mathrm{ml}$.) in $\mathrm{N}-\mathrm{H}_{2} \mathrm{SO}_{4}$ were sealed in glass ampules under $\mathrm{N}_{2}$ and heated at $105^{\circ}$ for various specified times. (b) $22.5 \mathrm{~N}-0.85 \mathrm{~N}^{-\mathrm{H}_{2}} \mathrm{SO}_{4}$ hydrolysate. Dry wall samples were soaked with $22.5 \mathrm{~N}-\mathrm{H}_{2} \mathrm{SO}_{4}$ and incubated at $30^{\circ}$ for $3 \mathrm{hr}$; the acid was diluted to $0.85 \mathrm{~N}$ and the suspension heated at $97^{\circ}$ for $4 \mathrm{hr}$. (c) $6 \mathrm{~N}-\mathrm{HCl}$ hydrolysate. Walls were suspended in $6 \mathrm{~N}-\mathrm{HCl}$, sealed in glass ampoules under $\mathrm{N}_{2}$, and hydrolysed at $105^{\circ}$ for $8 \mathrm{hr}$; excess $\mathrm{HCl}$ was removed in a desiccator over $\mathrm{NaOH}$ pellets under vacuum.

Neutral sugars were separated in descending paper chromatograms (Whatman no. 1) irrigated with $n$-butanol + pyridine + water $(6+4+3$, by vol.) for $30 \mathrm{hr}$ or longer. Sugars were revealed (aniline phthalate), eluted and measured (Wilson, 1959). Before chromatography, $\mathrm{H}_{2} \mathrm{SO}_{4}$ hydrolysates were neutralized with $\mathrm{BaCO}_{3}$ and de-ionized through a double-bed column of Dowex-1 (acetate form) and Dowex-50 (hydrogen form).

Amino sugars were determined in $6 \mathrm{~N}-\mathrm{HCl}$ hydrolysates by the Elson-Morgan method as described by Tracey (1955). Hexoses were estimated by the anthrone procedure of Dreywood as described earlier (Bartnicki-Garcia \& Nickerson, 1962). Reducing sugars were estimated by the method of Somogyi \& Nelson (Hodge \& Hofreiter, 1962). Glucose was assayed with a purified glucose oxidase reagent (Glucostat 'special', Worthington Biochemical Corp., Freehold, New Jersey, U.S.A.).

Search for uronic acids was made in $\mathrm{H}_{2} \mathrm{SO}_{4}$ hydrolysates by adsorption on a $10 \mathrm{ml}$. column of Dowex-1 (acetate form). A stepwise elution with increasing concentrations of acetic acid up to $4 \mathrm{~N}$ was used. A modified carbazole reagent was used to detect uronic acid in each of the $2 \mathrm{ml}$. fractions collected (Bitter \& Muir, 1962). Protein-N was estimated in $6 \mathrm{~N}-\mathrm{HCl}$ hydrolysates by a ninhydrin method described earlier (Bartnicki-Garcia \& Nickerson, 1962). Individual amino acids 
were resolved on two-dimensional paper chromatograms irrigated first with $n$-butanol + pyridine + water $(1+1+1$, by vol.); second, with phenol saturated with a $0.2 \mathrm{M}$ solution of $\mathrm{K}_{2} \mathrm{HPO}_{4}$ in water to which $0.01 \%(\mathrm{w} / \mathrm{v})$ 8-hydroxyquinoline was added. The solvent pair prescribed by Crook \& Johnston (1962) was also tested: $n$-butanol + acetic acid + water $(100+22+50$, by vol.) followed by phenol+water $\left(80+20\right.$, by vol.) in the presence of $\mathrm{NH}_{3}$ but without $\mathrm{NaCN}$. Quantitative amino acid analyses (Spackman, Stein \& Moore, 1958) were made in a Spinco 120B Automatic Amino Acid Analyser. Total phosphate was measured colorimetrically (Dryer, Tammes \& Routh, 1957). Lipids were extracted in two categories, free and bound, as described earlier (Bartnicki-Garcia \& Nickerson, 1962). Hyphal walls were chemically fractionated with acid and alkaline solutions as detailed previously (Bartnicki-Garcia \& Nickerson, 1962).

Physical techniques. Infrared spectra were determined in $\mathrm{KBr}$ pellets with a Perkin-Elmer Infracord spectrophotometer.

X-ray diagrams of samples spread on a glass microslide were obtained with a Norelco Phillipps recording diffractometer using $\mathrm{CuK}_{\alpha}$ radiation.

\section{RESULTS}

\section{Chemical analyses}

Carbohydrates. The anthrone procedure, with glucose as standard, served to assess the total amount of hexosan present in intact walls. To improve sample uniformity, dilute wall suspensions were homogenized by sonic oscillation immediately before pipetting. Nearly $90 \%$ of the hyphal wall dry weight of both species of Phytophthora was found to be anthrone-positive carbohydrate (Table 1).

Table 1. Hyphal wall composition of phytophthora

\begin{tabular}{|c|c|c|c|}
\hline \multirow[b]{2}{*}{ Component } & \multirow[b]{2}{*}{ Method } & \multicolumn{2}{|c|}{$\%$ wall dry weight } \\
\hline & & P. cinnamomi & P. parasitica \\
\hline Glucan* & Anthrone & $88 \pm 2$ & $86 \pm 2$ \\
\hline Mannose & Paper chromatography & $0 \cdot 6$ & 0.7 \\
\hline Glucosamine & Elson-Morgan & $0 \cdot 3$ & $0 \cdot 3$ \\
\hline Protein & Micro-Kjeldahl $\mathrm{N} \times 6.25$ & $3 \cdot 6$ & $4 \cdot 3$ \\
\hline Protein & Ninhydrin & $\mathbf{3} \cdot 4$ & $4 \cdot 1$ \\
\hline Free lipids & Direct extraction & $0 \cdot 3$ & $0 \cdot 2$ \\
\hline Bound lipids & Hydrolysis and extraction & $2 \cdot 1$ & 0.9 \\
\hline $\begin{array}{l}\text { Phosphorus } \\
\text { (as } \mathrm{H}_{2} \mathrm{PO}_{3} \text { ) }\end{array}$ & Semidine & $\mathbf{0} \cdot \mathbf{3}$ & 0.4 \\
\hline
\end{tabular}

Measurement of monosaccharide constituents of hyphal-wall polysaccharides was made in two types of $\mathrm{H}_{2} \mathrm{SO}_{4}$ hydrolysates; in neither case was sugar recovery complete. Direct hydrolysis in $\mathrm{N}_{-} \mathrm{H}_{2} \mathrm{SO}_{4}$ was insufficient to dissolve walls completely, even after prolonged digestion for $48 \mathrm{hr}$; by which time about a quarter of the wall carbohydrate remained insoluble, a quarter had been destroyed, and a half was in solution (Table 2). The soluble carbohydrate was composed almost exclusively of glucose as shown by determination of total and reducing sugar and by paper chromatography. 
The $22 \cdot 5-0 \cdot 85 \mathrm{~N}$-acid hydrolysis was much more efficient (Table 3); respectively, 93 and $87 \%$ of the initial polysaccharide of Phytophthora cinnamomi and P. parasitica was recovered in solution and only $0.1 \%$ remained insoluble. Paper chromatograms of this hydrolysate revealed glucose as the chief component. There was also a much smaller amount of two disaccharides subsequently identified as cellobiose and gentiobiose and traces of another one identified as laminaribose (Bartnicki-Garcia \& Lippman, to be published), plus a faint streak of unresolved oligosaccharides.

Table 2. Hydrolysis of hyphal walls of phytophthora in $\mathrm{N}-\mathrm{H}_{2} \mathrm{SO}_{4}$

\begin{tabular}{|c|c|c|c|c|}
\hline \multirow{3}{*}{$\begin{array}{c}\text { Carbohydrate in } \\
\text { hydrolysate }\end{array}$} & \multicolumn{4}{|c|}{$\%$ of initial total carbohydrate } \\
\hline & \multicolumn{2}{|c|}{ P. cinnamomi } & \multicolumn{2}{|c|}{ P. parasitica } \\
\hline & $18 \mathrm{hr}$ & $48 \mathrm{hr}$ & $18 \mathrm{hr}$ & $48 \mathrm{hr}$ \\
\hline Total* & $97 \cdot 8$ & $76 \cdot 1$ & $91 \cdot 8$ & $74 \cdot 4$ \\
\hline Soluble* & $\mathbf{5 9 \cdot 0}$ & $51 \cdot 1$ & $61 \cdot 7$ & $49 \cdot 0$ \\
\hline Insoluble† & $38 \cdot 8$ & $\mathbf{2 5 \cdot 0}$ & $30 \cdot 1$ & $25 \cdot 4$ \\
\hline Destroyed $\ddagger$ & $\mathbf{2 \cdot 2}$ & $23 \cdot 9$ & $\mathbf{8 \cdot 2}$ & $25 \cdot 6$ \\
\hline
\end{tabular}

* Determined with anthrone using glucose as standard. Values are \% anhydroglucose of initial glucan content in the wall (Table 1).

$\dagger$ Calculated: total - soluble; † Calculated: 100-total.

Table 3. Hydrolysis of hyphal walls of phytophthora with $22 \cdot 5-0 \cdot 85 \mathrm{~N}-\mathrm{H}_{2} \mathrm{SO}_{4}$

\begin{tabular}{|c|c|c|c|c|}
\hline \multirow[b]{2}{*}{ Carbohydrate* } & \multicolumn{2}{|c|}{ P. cinnamomi } & \multicolumn{2}{|c|}{ P. parasitica } \\
\hline & $\%$ wall & $\begin{array}{c}\% \text { initial } \\
\text { carbohydrate } \dagger\end{array}$ & $\%$ wall & $\begin{array}{c}\% \text { initial } \\
\text { carbohydrate } \dagger\end{array}$ \\
\hline Total soluble (anthrone) & $80 \cdot 7$ & $92 \cdot 6$ & $75 \cdot 6$ & $87 \cdot 5$ \\
\hline Glucose (glucostat) & $70 \cdot 9$ & $81 \cdot 4$ & 64.5 & $75 \cdot 6$ \\
\hline
\end{tabular}

Respectively, $\mathbf{8 1 . 4}$ and $\mathbf{7 5 . 6} \%$ of the total wall polysaccharide of Phytophthora cinnamomi and $\boldsymbol{P}$. parasitica were conclusively identified as D-glucose by the glucose oxidase assay. There are minimum values which do not include glucose diand oligo-saccharides present in the hydrolysates and do not take into account some glucose inevitably destroyed during hydrolysis. A trace of mannose, 0 6-6-0.7\% of the wall, was also found in both $\boldsymbol{P}$. cinnamomi and $\boldsymbol{P}$. parasitica. Inasmuch as the hydrolysates of wall polysaccharides of $\boldsymbol{P}$. cinnamomi and $\boldsymbol{P}$. parasitica revealed almost exclusively glucose and disaccharides thereof, the determination in intact walls of total carbohydrate by the anthrone method may be regarded as the best approximation to the actual glucan content of the wall (Table 1). In heavily loaded chromatograms (3.1 mg. walls) a vestigial spot appeared which had the colour of a pentose (aniline phthalate spray), the $\boldsymbol{R}_{F}$ value of ribose, and was visually estimated to be less than $0 \cdot 1 \%$ wall dry wt.

Uronic acids in $\mathrm{H}_{2} \mathrm{SO}_{4}$ hydrolysates were not detected.

Proteins. The protein content of mycelial walls of phytophthora was estimated by determining amino acid- $\mathrm{N}$ in $6 \mathrm{~N}$-hydrolysates and by micro-Kjeldahl determination of total nitrogen in intact walls (Table 1). Similar values were obtained 
in both determinations; the sum of individual amino acids determined in the automatic amino acid analyser (Table 4) also agreed with the above values. Amino acid quantities (Table 4) are given with the reservation that some destruction took place during hydrolysis as shown by humin formation.

Both two-dimensional paper chromatography and automatic column chromatography of hyphal wall hydrolysates revealed the common spectrum of protein amino acids, threonine being the most abundant. Hydroxyproline, an amino acid not usually found in fungal wall proteins, was shown in both paper and column chromatograms. Two weak unidentified ninhydrin-violet spots appeared in amino acid paper chromatograms of Phytophthora cinnamomi and $\boldsymbol{P}$. parasitica. $\boldsymbol{R}_{\text {alanine }}$ values were respectively 1.09 and 0.74 in $n$-butanol +acetic acid + water; 1.64 and 1.23 in phenol + water $+\mathrm{NH}_{3}$. They probably correspond to the unknown amino acid spots of $\boldsymbol{P}$. cactorum reported by Crook \& Johnston (1962). ( $\boldsymbol{R}_{\text {alanine }}$ values in this publication were misprinted; they should be 1.03 and 0.76 in $n$-butanol + acetic acid + water and 1.40 and 1.30 in phenol + water $+\mathrm{NH}_{3} ; \mathrm{I}$. R. Johnston, private communication).

Table 4. Overall amino acid composition of protein from hyphal walls of Phytophthora cinnamomi

$\begin{array}{lclc} & \begin{array}{c}\% \text { of total } \\ \text { amino acids* }\end{array} & & \begin{array}{c}\% \text { of total } \\ \text { amino acids* }\end{array} \\ \text { Threonine } & 14 \cdot 8 & \text { Glycine } & 4 \cdot 5 \\ \text { Glutamic acid } & 11 \cdot 1 & \text { Arginine } & 4 \cdot 2 \\ \text { Serine } & 9 \cdot 8 & \text { Ammonia } & \mathbf{3 \cdot 7} \\ \text { Aspartic acid } & \mathbf{T \cdot 0} & \text { Tyrosine } & \mathbf{2 \cdot 6} \\ \text { Alanine } & 9 \cdot 0 & \text { Phenylalanine } & \mathbf{2} \cdot 1 \\ \text { Proline } & 5 \cdot 5 & \text { Isoleucine } & 1 \cdot 8 \\ \text { Hydroxyproline } & 5 \cdot 0 & \text { Histidine } & 1 \cdot 1 \\ \text { Valine } & 5 \cdot 0 & \text { Cysteine } & 1 \cdot 1 \\ \text { Lysine } & 4 \cdot 7 & \text { Methionine } & 1 \cdot 1 \\ \text { Leucine } & 4 \cdot 5 & & \end{array}$

* The sum of amino acids recovered was $3 \cdot 79 \%$ of the initial wall dry weight.

Amino sugars. A glucosamine peak, representing $0 \cdot 20 \%$ of the wall of Phytophthora cinnamomi, and a much smaller peak, presumably galactosamine, were detected during the automatic analysis of amino acids. Elson-Morgan determinations on $6 \mathrm{~N}$-hydrolysates confirmed the existence of a small amount of amino sugar in both phytophthora species (Table 1).

Lipids. A small amount of lipid, mainly of the bound type, was detected in the walls of both phytophthora species (Table 1).

Various. Determination of total phosphorus indicated phosphate content of about $\mathbf{0 . 3} \%$ (Table 1 ). Hot $\mathrm{N}-\mathrm{KOH}$ extracts of walls showed sharp absorption peaks at $263 \mathrm{~m} \mu$, suggesting the possible presence of $0.8 \%$ nucleic acid components (calculated at an average $\epsilon$ of 8800).

Chemical fractionation. Hyphal walls were fractionated by two different methods. The distribution of carbohydrates (Table 5) and protein (Table 6) was investigated by anthrone and ninhydrin assays. Fractionation method I indicated that even at high temperatures the hyphal-wall glucans were alkali-insoluble; likewise, hot acetic acid did not dissolve any appreciable quantity of glucan. In the same 
fractionation, over half of the wall protein was dissolved by cold alkali and most of the remainder dissolved in hot alkali. A small proteinaceous residue was left associated with the insoluble glucan. Fractionation method II revealed that a large portion of the wall glucan (61-66\%) was soluble in hot dilute acid. Consecutive extraction of hyphal walls with hot acid and hot alkali left only about $20 \%$ of insoluble glucan. Recovery of carbohydrate in this method was incomplete, probably due to destruction of glucan by hot alkali after walls had first been treated with hot acid, a situation also observed for the glucan of Mucor rouxii spore walls (Bartnicki-Garcia \& Reyes, 1964).

Table 5. Distribution of carbohydrates in hyphal wall fractions of phytophthora

\begin{tabular}{|c|c|c|c|}
\hline \multirow[b]{2}{*}{ Method } & \multirow[b]{2}{*}{ Fraction } & \multicolumn{2}{|c|}{$\%$ of initial carbohydrate* } \\
\hline & & P. cinnamomi & P. parasitica \\
\hline \multirow[t]{5}{*}{ I } & Cold N-KOH & $\mathbf{2 \cdot 7}$ & $2 \cdot 1$ \\
\hline & Hot N-KOH & $\mathbf{3 \cdot 2}$ & $\mathbf{3 \cdot 3}$ \\
\hline & Hot $\mathrm{N}$-acetic acid & 0.2 & $\mathbf{0 . 3}$ \\
\hline & Residue & $93 \cdot 2$ & $95 \cdot 6$ \\
\hline & Sum & $99 \cdot 3$ & $101 \cdot 3$ \\
\hline \multirow[t]{5}{*}{ II } & Cold N-HCl & $0 \cdot 2$ & $\mathbf{0 \cdot 3}$ \\
\hline & Hot N-HCl & $61 \cdot 3$ & 65.9 \\
\hline & Hot N-KOH & $\mathbf{3 \cdot 2}$ & $\mathbf{3} \cdot \mathbf{0}$ \\
\hline & Residue & $\mathbf{2 1} \cdot 2$ & $19 \cdot 7$ \\
\hline & Sum & $\mathbf{8 5 \cdot 9}$ & $\mathbf{8 8 . 9}$ \\
\hline
\end{tabular}

* Determined with anthrone reagent and calculated as \% anhydroglucose of the initial glucan values shown in Table 1.

Table 6. Distribution of protein in hyphal walls of phytophthora fractionated according to Method I (Table 5)

\begin{tabular}{|c|c|c|}
\hline \multirow[b]{2}{*}{ Fraction } & \multicolumn{2}{|c|}{$\%$ of total protein* } \\
\hline & P. cinnamomi & P. parasitica \\
\hline Cold N-KOH & $\mathbf{5 9 \cdot 5}$ & $63 \cdot 1$ \\
\hline Hot N-KOH & $\mathbf{2 7 \cdot 2}$ & $21 \cdot 4$ \\
\hline Hot $\mathrm{N}$ - acetic acid & $5 \cdot 1$ & $\mathbf{5 \cdot 9}$ \\
\hline Residue & $8 \cdot 2$ & $9 \cdot 6$ \\
\hline
\end{tabular}

* Determined by the ninhydrin method and calculated on the basis of the total protein values (ninhydrin) from Table 1.

Extraction with $\mathbf{1 7 . 5} \% \mathrm{NaOH}$, under $\mathrm{N}_{2}$, is commonly used in cellulose technology to determine and separate $\alpha$-cellulose from low molecular weight celluloses and other carbohydrates (Corbett, 1963). Accordingly, only 3.4\% of Phytophthora cinnamomi walls dissolved as anthrone-positive carbohydrate. It may not be concluded, however, that the portion of wall glucan insoluble in $17.5 \% \mathrm{NaOH}$ is $\alpha$-cellulose since it is known that other glucans, notably yeast cell-wall glucan (Chung \& Nickerson, 1954), are highly insoluble in concentrated alkali.

Infrared spectra. Intact walls of Phytophthora cinnamomi and $\boldsymbol{P}$. parasitica showed nearly identical spectra, corroborating their chemical similarity. They showed absorption peaks at about $890 \mathrm{~cm} .^{-1}$, indicative of $\beta$-linked polysaccharide. 
There was no evidence of absorption in the $\alpha$-glycoside region at $844 \mathrm{~cm}^{-1}$ (Barker, Bourne \& Whiffen, 1956). The spectra of isolated walls was compared with that of crystalline cellulose I (Whatman $\alpha$-cellulose powder for chromatography); there was a general resemblance, but the wall spectra differed noticeably in the blurring of peak sharpness in the $1000-1500 \mathrm{~cm}^{-1}$ region (Fig. 3). Extraction of walls with cold $\mathrm{N}-\mathrm{KOH}$ for $1 \mathrm{hr}$, followed by $0.5 \mathrm{~N}-\mathrm{KOH}$ at $100^{\circ}$ for $30 \mathrm{~min}$., improved the resemblance slightly; minor peaks at $1510-1540 \mathrm{~cm}^{-1}$ (amines and/or aromatics) disappeared, and other small peaks were enhanced. The treatment removed most of the protein and lipid, leaving a wall composed of glucan almost entirely. Infrared spectra of Phytophthora walls showed a much greater similarity to the spectra of amorphous cellulose (cf. O'Connor, DuPre \& McCall, 1957) than to that of cellulose $\mathbf{I}$.

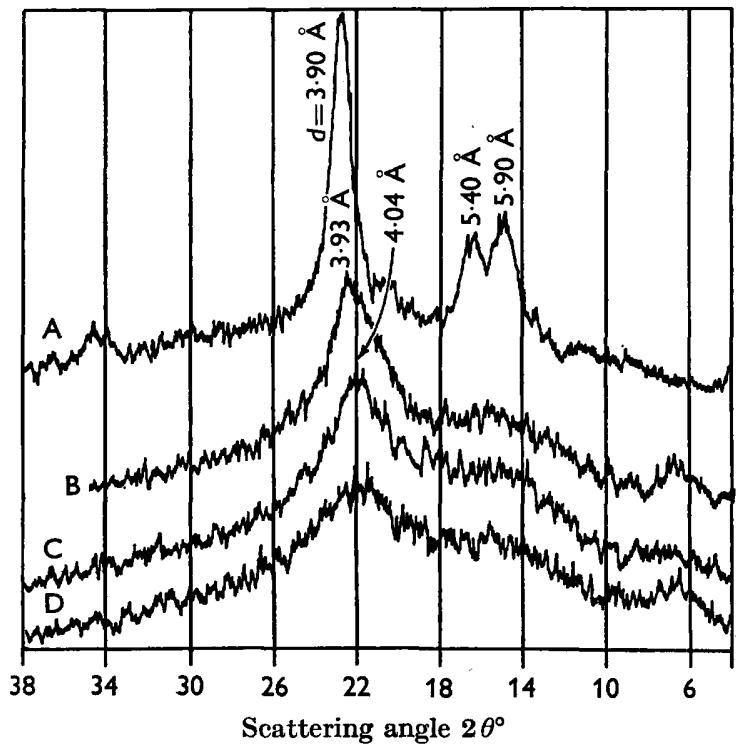

Fig. 1

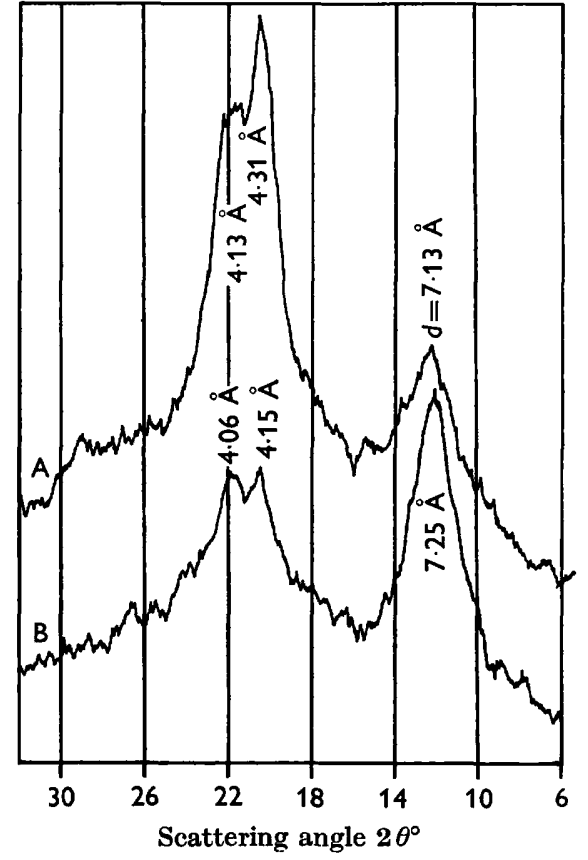

Fig. 2

Fig. 1. X-ray diagrams. A, Cellulose I; B, insoluble residue after extraction of Phytophthora cinnamomi hyphal walls with hot $\mathrm{N}-\mathrm{HCl}$; C, intact hyphal walls of $P$. cinnamomi; D, isolated hyphal walls of $P$. parasitica. Tracings vertically displaced for clarity.

Fig. 2. X-ray diagrams. A, Cellulose II regenerated from Whatman cellulose I; B, material regenerated from Phytophthora cinnamomi hyphal walls. Tracings vertically displaced for clarity.

$X$-ray diagrams. Intact walls showed very weak reflexions suggestive of cellulose $\mathbf{I}$ (Fig. 1). Reflexion sharpness did not improve after extraction with $\mathrm{KOH}$ as specified above for infrared spectra. Since walls thus treated consist almost entirely of glucan polymers, cellulose crystallinity in the phytophthora walls is either poor or is masked by amorphous glucans. Definite evidence for the presence of cellulose was obtained by twice extracting walls of Phytophthora cinnamomi 
with Schweizer's cellulose solvent (Jayme \& Lang, 1963) for $24 \mathrm{hr}$ under $\mathrm{N}_{2}$. Upon acidification of the solvent, a precipitate was obtained which showed X-ray spacings similar to that of cellulose II prepared from Whatman cellulose powder by identical handling (Fig. 2). There was, however, a divergency in the relative intensity of the reflexions. This discrepancy may be an artifact due to lack of randomness in the spatial orientation of cellulose crystallites in the specimen slides.

Anthrone determinations showed that only $11 \%$ of the wall regenerated as cellulose II and that $63 \%$ did not dissolve at all in Schweizer's reagent; the unaccounted glucan (14\% of the wall) probably remained in solution.

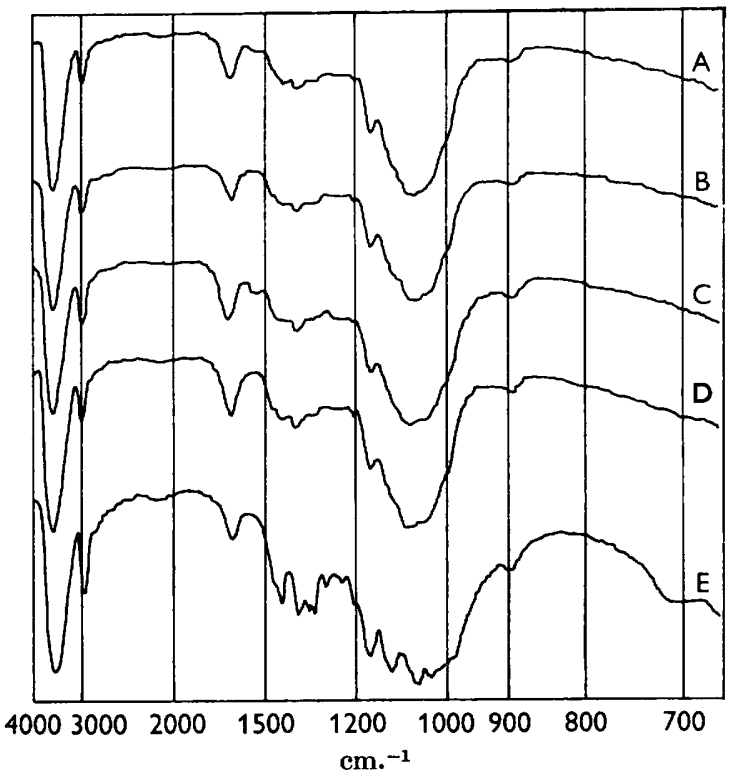

Fig. 3

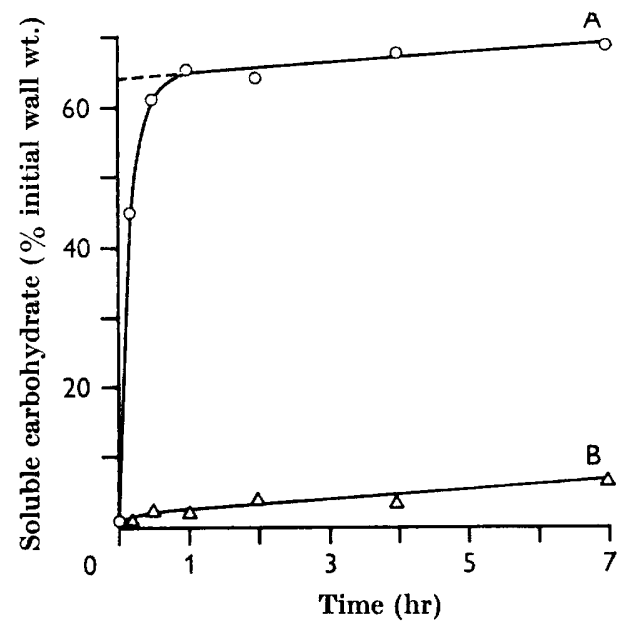

Fig. 4

Fig. 3. Infrared spectra: A, isolated hyphal walls of Phytophthora cinnamomi; $\mathbf{B}$, as A but extracted with $\mathrm{KOH}$; C, isolated hyphal walls of $P$. parasitica; D, as $\mathrm{C}$ but extracted with $\mathrm{KOH}$; E, cellulose I. Tracings vertically displaced for clarity.

Fig. 4. Comparative rate of hydrolysis of isolated hyphal walls of Phytophthora cinnamomi (curve A) and Whatman cellulose powder (curve B) in $\mathrm{N}-\mathrm{HCl}$ at $97^{\circ}$.

The single, broad, X-ray peak of negative walls (4.04 $\AA$ ) approximated to the main reflexion of authentic cellulose $I(3.90 \AA)$ and disappeared upon extraction with Schweizer's solvent, leaving an isotropic glucan residue. When, on the other hand, the amorphous glucan was first removed from walls, by $\mathrm{N}$-acid digestion (see below), a residue was left which exhibited a slightly more pronounced X-ray spectrum than did native walls, with its main reflexion (3.93 $\AA$ ) closer to that of cellulose I. It may, therefore, be concluded that cellulose I of relative low crystallinity exists in the phytophthora walls.

Acid-extraction of wall glucans. Since hot dilute mineral acid dissolved a major portion of the glucan from hyphal walls of phytophthora (Table 5), the kinetics of hyphal wall solution of Phytophthora cinnamomi by $\mathrm{N}-\mathrm{HCl}$ at $97^{\circ}$ was studied. As depicted in Fig. 4, 61.2\% of the wall (i.e. $70 \%$ of the total polysaccharide) dis- 
solved within $30 \mathrm{~min}$. Thereafter the extraction rate decreased sharply to a slow constant rate. The experiment was ended at $7 \mathrm{hr}$, by which time $69.5 \%$ of the wall had dissolved (i.e. $80 \%$ of the total polysaccharide). On the other hand, only $6.5 \%$ Whatman cellulose dissolved under the same conditions. To calculate the amount of glucan readily extracted by $\mathrm{HCl}$, the upper portion of the curve corresponding to the hydrolysis of a resistant polysaccharide was extrapolated to zero time. Thus, $63 \%$ of the wall consists of a glucan readily soluble in hot dilute mineral acid. Hence, about $25 \%$ of the wall corresponded to a relatively acid-insoluble glucan whose X-ray spectrum (Fig. 1) indicated that it was partly, if not entirely, cellulose I.

The acid-soluble glucan was also rapidly hydrolysed; thus $84 \%$ of the total carbohydrate extracted by $\mathrm{N}-\mathrm{HCl}$ in $\mathbf{3 0} \mathrm{min}$., was dialysable. Under less drastic conditions, using several brief extractions with hot $0 \cdot 1 \mathrm{~N}-\mathrm{HCl}$, depolymerization was considerably decreased and a soluble non-dialysable glucan(s) was isolated. Preliminary measurement of optical rotation in water $[\alpha]_{D}^{23}-3^{\circ}$ suggests it was predominantly a $\beta$-glucan.

\section{DISCUSSION}

As in the case for the chitinous cell walls of moulds, the cellulosic hyphal walls of Phytophthora cinnamomi and $\boldsymbol{P}$. parasitica also consist of polysaccharide, protein, and lipid; they are, however, somewhat simpler than the hyphal walls of a chitinous Phycomycete such as Mucor rouxii, which contains a wider variety of building blocks (Bartnicki-Garcia \& Nickerson, 1962); in phytophthora, glucose polymers account for nearly $90 \%$ of the hyphal walls. As expected, cellulose was identified in the hyphal walls of Phytophthora but its exact content is not known. Qualitative evidence for cellulose includes the following observations. Release of large amounts (about $20 \%$ ) of cellobiose during enzymic digestion of $\boldsymbol{P}$. cinnamomi walls with a crude cellulase from Streptomyces (Bartnicki-Garcia \& Lippman, to be published); very limited solubility of walls in $\mathbf{1 7 . 5} \% \mathrm{NaOH}$; partial solubility of hyphal walls in Schweizer's reagent and subsequent regeneration of a polymer with an X-ray pattern similar to cellulose II; X-ray diagrams of intact walls suggestive of cellulose I.

A quantitative measurement of cellulose would be arbitrary and largely dependent on which physical or chemical properties were used to define cellulose (Ott \& Tennent, 1954). Furthermore, the notion of having true cellulose as a chemical entity separate from the other wall glucans may be artificial, for it is possible that the hyphal walls of phytophthora consist of one single glucan species with amorphous regions and a cellulose-like core. More work obviously is needed to clarify this point.

Separation of two glucan fractions from hyphal walls of Phytophthora cinnamomi was accomplished by treatment with hot dilute mineral acid. Thus were obtained a readily soluble, rapidly hydrolysable amorphous glucan comprising $63 \%$ of the wall, and a much more acid-resistant polymer representing $25 \%$ of the wall. It is not yet known whether the acid treatment cleaved a single native glucan into these two types. In any event, the acid-resistant glucan showed $\mathrm{X}$-ray reflexions approximating that of cellulose $I$ and may thus be considered to represent that portion of the phytophthora wall most closely resembling native crystalline cellulose of higher plants.

Release of gentiobiose and laminaribose during chemical or enzymic hydrolysis 
(Bartnicki-Garcia \& Lippman, to to be published) indicated the presence of $\beta(1 \rightarrow 6)$ and $\beta(1 \rightarrow 3)$ linkages and opens the possibility that two types of glucan exist in the wall-a homogenous $\beta(1 \rightarrow 4)$ cellulose-like polymer, and an amorphous glucan containing an as yet undetermined number of $\beta(1 \rightarrow 3)$ and $\beta(1 \rightarrow 6)$ linkages.

Although Phytophthora cinnamomi was examined in greater detail, the data on $\boldsymbol{P}$. parasitica is sufficient to conclude that both species have a similar hyphal-wall composition. Yet, differences in certain properties such as the propensity of $\boldsymbol{P}$. parasitica walls to agglutinate and the more intense staining of $\boldsymbol{P}$. cinnamomi walls with Lugol's solution may correspond to significant chemical differences. Hyphal wall analyses of $\boldsymbol{P}$. cinnamomi and $\boldsymbol{P}$. parasitica agree with the qualitative findings of Crook \& Johnston (1962) on the sugars and amino acids present in hydrolysates of $\boldsymbol{P}$. cactorum, except for ribose which was only vaguely detectable in the former species.

Glucosamine, major component of most mould walls, was found in the cellulosic walls of phytophthora in such a small quantity as to question its relevance as a structural wall element. This finding agrees with Frey's (1950) failure to obtain $\mathrm{X}$-ray evidence for chitin in various phytophthora cultures. Thomas (1943) claimed the presence of chitin in Phytophthora cinnamomi on the basis of a positive chitosan staining reaction; this conclusion was challenged by Frey (1950) and seems untenable in view of the present work. Interestingly, much earlier Dastur (1913), who also used cytochemical tests, found staining-reaction evidence for cellulose, but not for chitin, in $\boldsymbol{P}$. parasitica.

Hydroxyproline is not known to occur in the walls of chitinous fungi. Its presence in fungi with cellulosic walls such as phytophthora and saprolegnia (Crook \& Johnston, 1962) may have special significance since a similar concurrence is conspicuously apparent in the cell wall of higher plants, where hydroxyproline is a characteristic component (Lamport \& Northcote, 1960). Although assumed to be minimal, the exact extent to which the preparative procedure altered the composition of the hyphal walls of phytophthora by addition or deletion of components is not known. Undoubtedly, the physical technique used in this study for cell-wall preparation is superior to the old method of exhaustive chemical extraction of whole organisms which only the most inert substances endured. Nevertheless, upon hyphal breakage, even though the mycelium was coenocytic, cytoplasmic contents did not flow out entirely; solid plugs remained whose dislodgement necessitated the strong action of a sonic oscillator. By this procedure, all visible cytoplasmic debris was essentially, but not entirely, eliminated. Minute residues, whose contribution to the composition of the walls has been assumed to be negligible, were occasionally seen. On the other hand, the extensive action of sonic oscillation may have selectively removed or modified some wall components to an undetermined degree.

I wish to acknowledge the excellent technical assistance of Miss Dorothy Campos and Mrs Eleanor Lippman, and the kind co-operation of Dr J. B. Mudd in the automatic analysis of amino acids. This investigation was supported in part by a research grant (AI-06205) from the National Institutes of Health, Bethesda, Maryland, U.S.A. 


\section{REFERENCES}

Aronson, J. M. \& Machlis, L. (1959). The chemical composition of the hyphal walls of the fungus Allomyces. Am. J. Bot. 46, 292.

Aronson, J. M. \& Preston, R. D. (1960). An electron microscopic and X-ray analysis of the walls of selected lower Phycomycetes. Proc. $R$. Soc. B, 152, 346.

Barker, S. A., Bourne, E. J. \& Whiffen, D. H. (1956). Use of infrared analysis in the determination of carbohydrate structure. Meth. biochem. Analysis, 3, 213.

Bartnicki-Garcia, S. \& Nickerson, W. J. (1962). Isolation, composition, and structure of cell walls of filamentous and yeast-like forms of Mucor rouxii. Biochim. biophys. Acta, 58, 102.

Bartnicki-Garcia, S. \& Reyes, E. (1964). Chemistry of spore wall differentiation in Mucor rouxii. Archs Biochem. Biophys. 108, 125.

Bitter, T. \& Murr, H. M. (1962). A modified uronic acid carbazole reaction. Analyt. Biochem. 4, 330.

Chung, C. W. \& Nickerson, W. J. (1954). Polysaccharide synthesis in growing yeasts. J. biol. Chem. 208, 395.

Conbert, W. M. (1963). Determination of alpha-cellulose content of cotton and wood cellulose. In Methods in Carbohydrate Chemistry. Ed. by R. L. Whistler. Vol. 3. p. 27. New York: Academic Press.

Crook, E. M. \& Johnston, I. R. (1962). The qualitative analysis of the cell walls of selected species of fungi. Biochem. J. 83, 325.

Dastur, J. F. (1913). On Phytophthora parasitica nov.spec. A new disease of the castor oil plant. Mem. Dep. Agric. India bot. ser. 5, 177.

Dryer, R. L., TAmmes, A. E. \& Routh, J. I. (1957). Determination of phosphorus in body fluids. J. biol. Chem. 225, 177.

Frey, R. (1950). Chitin and Zellulose in Pilzzellwänden. Ber. schweiz. bot. Ges. 60, 199.

Fuller, M. S. \& Barshad, I. (1960). Chitin and cellulose in the cell walls of Rhizidiomyces sp. Am. J. Bot. 47, 105.

Hamilton, P. B. \& KNight, S. G. (1962). An analysis of the cell walls of Penicillium chrysogenum. Archs Biochem. Biophys. 99, 282.

Hodge, J. E. \& Hofreiter, B. T. (1962). Determination of reducing sugars and carbohydrates. In Methods in Carbohydrate Chemistry. Ed. by R. L. Whistler \& M. L.Wolfram. Vol. 1. p. 380. New York: Academic Press.

HonIkoshi, K. \& ImA, S. (1964). Studies of the spore coats of fungi. I. Isolation and composition of the spore coats of Aspergillus oryzae. Biochim. biophys. Acta, 83, 197.

JaYme, G. \& Lang, F. (1963). Cellulose solvents. In Methods in Carbohydrate Chemistry, Ed. by R. L. Whistler. Vol. 3. p. 75. New York: Academic Press.

KREGER, D. R. (1954). Observations on cell walls of yeasts and some other fungi by X-ray diffraction and solubility tests. Biochim. biophys. Acta, 13, 1.

Lamport, D. T. A. \& Northcote, D. H. (1960). Hydroxyproline in primary cell walls of higher plants. Nature, Lond. 188, 665.

O'Connor, R. T., Dupre, E. F. \& MCCALL, E. R. (1957). Infrared spectro-photometric procedure for analysis of cellulose and modified cellulose. Analyt. Chem. 29, 998.

Otт, E. \& Tennent, H. G. (1954). Introduction, in Cellulose and Cellulose Derivatives. Ed. by E. Ott, H. M. Spurlin \& M. W. Grafflin. Part I, p. 1. New York: Interscience Publishers.

Potgieter, H. J. \& Alexander, M. (1965). Polysaccharide components of Neurospora crassa hyphal walls. Can. J. Microbiol. 11, 122.

Russell, D. W., Sturgeon, R. J. \& Ward, V. (1964). Preparation and properties of a hyphal wall fraction from Pithomyces chartarum. J. gen. Microbiol. 36, 289.

Spackman, D. H., Stein, W. H. \& Moore, S. (1958). Automatic recording apparatus for use in the chromatography of amino acids. Analyt. Chem. 30, 1190.

Thomas, R. C. (1943). Composition of fungus hyphae. IV. Phytophthora. Ohio J. Sci. 43, 135. 
Tracey, M. V. (1955). In Modern Methods of Plant Analysis. Ed. by K. Paech and M. V. Tracey. Vol. 2, p. 264. Berlin: Springer-Verlag.

Wessels, J. G. H. (1965). Morphogenesis and biochemical processes in Schizophyllum commune. Wentia, 13, 1.

WETtstein, F. von (1921). Das Vorkommen von Chitin und seine Verwertung als systematischphylogenetisches Merkmal im Pflanzenreich. Sber. Akad. Wiss. Wien, Abt. I, 130, 3.

WiLson, C. M. (1959). Quantitative determination of sugars on paper chromatograms. Analyt. Chem. 31, 1199. 